\title{
The Influence of Physical Cohesion on Scour around a Monopile
}

\author{
R.J. Schindler \& S. Stripling \\ Plymouth University, UK \\ R.J.S. Whitehouse \& J.M. Harris \\ HR Wallingford Ltd., Wallingford, UK
}

\begin{abstract}
We present experiments that systematically examine how the addition of physically cohesive clay to sand affects scour evolution around a monopile in a current. Repeated centreline transects are used to show the changes in scour depth and excavated material over time. Combined with 3D plots of the final equilibrium morphology, the results conclusively prove that clay content causes a progressive reduction in the equilibrium depth, excavated area and that timescales of scour increase with clay content. Winnowing of clay particles from the sand matrix is a pre-requisite for scour and differences in clay content influence the rate and extent of winnowing, ultimately controlling equilibrium scour morphology. The strong linear relationships between clay content and equilibrium scour parameters offers a simple index on which to modify existing scour prediction methods. It follows that improved predictions of scour development can reduce manufacturing costs and related logistical expenses of structure operations in fluvial, coastal or offshore environments.
\end{abstract}

\section{INTRODUCTION}

The design, fabrication, and installation of offshore windfarm (OWF) foundations comprises $\sim 30 \%$ of total capital expenditure (CAPEX), second only to the turbine itself. Consequently, innovation in new foundation designs that are cheaper to fabricate and install offer the second greatest potential for reducing costs after turbine manufacture (Renewables Advisory Board 2010, The Carbon Trust 2014).

The optimal design and construction of monopilebased OWFs requires an accurate estimate of the maximum scour depth during their anticipated lifespan. A reasonable understanding of the physical processes leading to scour development around monopiles exists for non-cohesive sediment (e.g. Melville, 1997; Sheppard et al. 2004). Installation guidance generally states expected scour depth, $S$, as a ratio of circular pile diameter, $D$. DNV's (2010) value of $S / D=1.3$ is considered a European industry standard for predicting scour around monopiles. However, the level of uncertainty is \pm 0.7 . Den Boon et al. (2004) state maximum scour is $S / D=1.75$ based on lab experiments. In both cases predictions are based on cohesionless sand. Empirical predictions such as the HEC18 methodology (e.g. Richardson \& Davis 1995) are widely adopted for predicting maximum scour depth yet typically assume a unimodal, homogenous cohesionless substrata.

Fine-grained mud, made up of silt- and clay-sized particles, is the most abundant material on Earth's surface (Healy et al. 2002). Clay platelets aggregate due to mass attractive London-van de Waals forces and inter-particle electrostatic bonding of cohesive particles, increasing resistance to erosion (Mehta 2014).

Extensive sedimentological investigations concerning the erosion threshold of estuarine and coastal deposits have been undertaken independently into cohesive muds (see Dade et al. 1992, Mehta 1993, Whitehouse et al. 2000). Several empirical equations have been proposed for critical erosion thresholds in clays which can be adopted for mixed-cohesive sediments (e.g. Dunn 1959, Lyle \& Smerdon, 1965). However, only limited studies of scour in sand-clay mixtures exist. In some cases sand content was negligible (Briaud et al. 1999; Ting et al. 2001). Molinas \& Hosny (1999) examine monopile scour in sandclay mixtures for montmorillonite contents of 5 $40 \%$ and Asnari et al. (2002) used kaolinite across $10-60 \%$.

Typically offshore sediments are a mixture of cohesionless sands and gravels and cohesive mud with lithogenous, biogenous or hydrogenous origins and are multi-modal in their size distribution. In a sand matrix these molecular-scale physiochemical forces cause colliding grains to bond and form aggregates and become a control on sediment transport, erosion and deposition (Debnath and Chaudhuri 2010). It follows that a sediment matrix with clay or silt content (herein known as 'mixed cohesives') will be more difficult to erode than a cohesionless matrix because clay particles exhibit edge-to-plate bonds and stack between sand grains, filling voids (e.g. Alizadeh 1974, Parsons et al. 2016). 
Limited field observations have shown that physical cohesion imparted by mud can cause a dramatic reduction on the rate and, potentially, the equilibrium depth of scour (e.g. Whitehouse et al. 2011). They determined from the data available at that time, that only six of the 115 monopiles studied had $S / D \geq$ 1.3. This variability and the inaccuracies of prediction can typically be attributed to a lack, or absence of, sedimentological and geological information within those predictive models (Van den Eynde et al. 2010, Marine Management Organisation 2014) because certain sediments yield smaller scour depths than predicted. Indeed, post-installation data show that where geological, sedimentary and hydrodynamic conditions are similar, OWFs have similar responses in terms of scour (Harris and Whitehouse 2014).

The low scour rate in clays is associated with the fact that it takes a large number of shear stress cycles to overcome the hydrostatic and electromagnetic bonds between clay particles. Thus, the understanding of scour in mixed cohesive sediments is limited due to the complex nature of inter-related parameters needed for characterization. Ariathurai \& Arulanandan (1974) and van Ledden et al. (2004) use a heuristic approach to derive an empirical erosion parameter to determine the erosion rate using the balance between actual and critical shear stress. Partheniades (1965) relates critical shear stress to packing density and particle size and Panagiotopoulos et al. (1997) relate erosion behaviour to the internal friction angle of sediments, where mud contents above $30 \%$ reduces the friction angle compared with sands. Smerdon $\&$ Beasley (1959) incorporate the plasticity index to define critical shear stress but ignore packing density. More recently, it has been shown that physical cohesion significantly modifies sediment transport processes in coastal and offshore environments (e.g. Jacobs et al. 2011, Schindler et al. 2015, Parsons et al. 2016).

It is now recognised that it is difficult to predict scour characteristics for complex marine sediments on the basis of a few index properties (Briaud et al. 1999). The 'Earth Materials' approach (see Annandale 1995, Harris et al. 2010) that quantifies the potential for different layers in marine soils to erode is dependent on knowing multiple geotechnical parameters for each soil layer. This information is sometimes difficult to obtain and the vast variation in properties of clay, even on an intra-site basis (e.g. Briaud et al. 1999), make the resolution of sampling required to properly characterize marine soils on a site-by-site basis unfeasible. Alternatively, the SRICOS method (Briaud et al. 1999; also reviewed by Harris et al. 2010) circumvents parameterisation of sediment complexity by assuming the sediment is comprised of clay. It empirically predicts maximum scour depth at a cylindrical monopile under a steady current assuming an homogenous substrate and water depth greater than double the monopile diameter.

In the absence of detailed geotechnical information the prediction of scour around a monopile is limited to methods that assume a cohesionless substrate or a fully-cohesive clay substrate. We can conclude that comprehensive information is not yet available for the accurate prediction of scour characteristics around monopiles and that current predictive methods are based on limited data (Kothyari 2008).

Thus, there is a considerable opportunity for innovative research to influence what becomes the long-term industry-standard solution for scour prediction in mixed cohesive substrata. The focus in this study is determining how physical cohesion imparted by clay within a cohesionless matrix influences scour development. We hypothesize that scour rate, equilibrium depth and lateral extent will reduce in proportion to the amount of clay added to a sand matrix, ultimately until scour no longer occurs.

\section{METHODS}

\subsection{Flume, Monopile \& Sediment Properties}

Experiments were performed in Plymouth University's COAST Laboratory's recirculating sediment flume $(l 20.0 \times w 0.6 \mathrm{~m})$ which includes a recessed scour pit $\left(l 2.1 \times w 0.36 \times d_{\text {sed }} 0.26 \mathrm{~m}\right.$; Figure 1$)$. Bespoke sediment trays were fitted with a model monopile and then filled with different substrata before insertion into the sediment pit. The model monopile was $0.048 \mathrm{~m}$ in diameter, $D$. Assuming a prototype monopile diameter of $2.0 \mathrm{~m}$ yields a geometric ratio of 41.67 . When applied to a $10 \mathrm{~m}$ prototype water depth, $d$, this yields a model depth of 0.24 $\mathrm{m}$. The monopile was segmented, allowing the section above the original sediment surface to be removed. This allowed detailed scans of the final scour morphology to be obtained without obstruction of the protruding monopile. Fresh water was used in the tests.

Six different substrata were examined: A baseline 'Sand Only' run $\left(D_{50}=230 \mu \mathrm{m}\right)$ plus five sand-clay (Polwhite E kaolinite, $D_{50}=3.5 \mu \mathrm{m}$ ) mixtures spanning clay contents of $2.5 \%<f_{0}<15 \%$ (Table 1 ). This range represents the transition from cohesionless to cohesive erosion (Debnath et al. 2007). Each fraction was mixed into a wet slurry using $12.5 \mathrm{~L}$ of water in a motorized drum mixer, added to the sediment tray and left to de-water and consolidate in air for $12 \mathrm{~h}$. Thereafter, the sediment tray was inserted into the sediment pit and saturated for $12 \mathrm{~h}$. This was done to saturate the sediment bed with water and allow cohesive and non-cohesive matrices to develop bonds closer to those in nature (e.g. Debnath et al. 2007). 


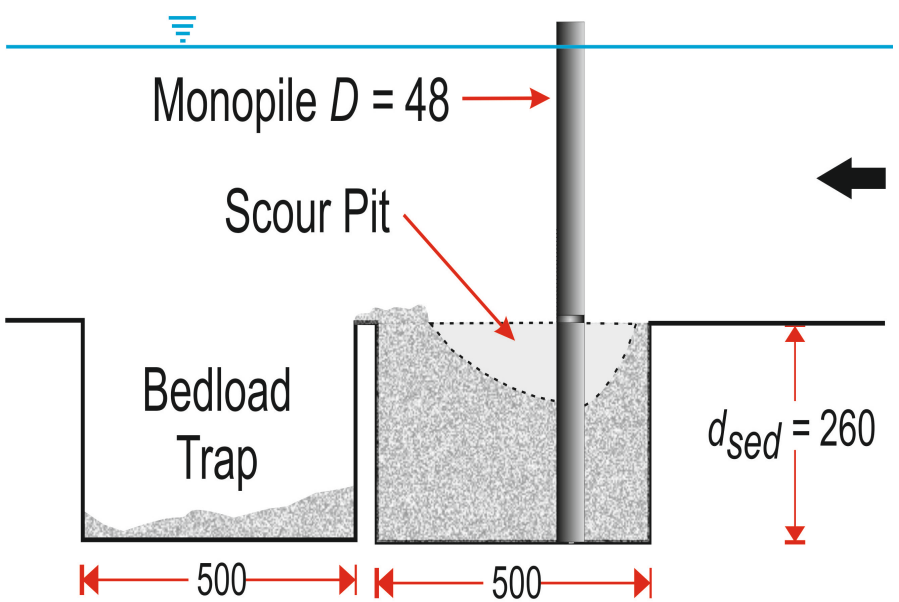

Figure 1. Side view schematic of experimental setup. All units in $\mathrm{mm}$.

Initial surface shear strength was measured using a $20 \mathrm{~mm}$ diameter shear vane in the uppermost 25 $\mathrm{mm}$ of sediment at ten locations towards the margins of each substrata prior to each experiment and averaged to yield a representative mean shear strength value, $\tau$. The relative contributions of sand and clay bedload fractions were established through sieving of bedload collected at the end of each experimental run to obtain each fraction's mass.

\subsection{Flow Conditions}

Trial scour experiments in pure sand were used to select the velocity that maximised the rate of scour (i.e. an adverse pressure gradient sufficiently strong to induce horseshoe vortices to develop) without inducing live bed conditions. Subsequently, a Nortek Vectrino 2+ acoustic Doppler velocity profiler was used to characterize the velocity profile at the centreline above the flat flume bed at the position of the monopile. The depth-mean downstream velocity, $U$, was $0.20 \mathrm{~m} \mathrm{~s}^{-1}$, shear velocity, $U^{*}=0.014 \mathrm{~m} \mathrm{~s}^{-1}$, bed shear stress, $\tau_{b}=0.198 \mathrm{~N} \mathrm{~m}^{-2}$, Froude number, $\mathrm{Fr}=$ 0.13 , depth-mean Reynolds number, $R e=26,880$ and depth-mean pile Reynolds number, $R e_{D}=9680$. Input velocity was constant and bed slope zero throughout each experiment.

Previous experiments assessing scour around monopiles in currents have shown that achieving a stabilised, equilibrium scour is extremely time consuming (e.g. Yanmaz \& Altinbilek 1991, Briaud et al. 1999) and consequently limits the number of experimental runs that can be undertaken. This was also the case here, particularly for high clay content substrates. Initial experiments where $f_{0}=12.5 \%$ and $15 \%$ were undertaken over $5 \mathrm{~h}$. Resulting data indicated that $3 \mathrm{~h}$ was sufficient to reach equilibrium scour depth and in subsequent experiments where $2.5 \%<f_{0}<10 \%$ the experiments lasted $3 \mathrm{~h}$. The Sand Only experiment lasted $5 \mathrm{~h}$ to provide comparison to all runs (discussed in 3.2).

\subsection{Scour Measurements}

Scour development was measured using an HR Wallingford laser point gauge mounted on a manual traverse. The sampling rate was $10 \mathrm{~Hz}$ and each measurement was $1.0 \mathrm{~s}^{-1}$. The laser outputs data as voltage which requires conversion to millimetres using a linear calibration equation. Measurements were made along the $530 \mathrm{~mm}$ centreline at $10 \mathrm{~mm}$ increments. Once the current was applied measurements were made at pre-set intervals that were biased towards initial scour development. The laser head was removed from the water between transects (which took approximately $120 \mathrm{~s}$ to complete). Each transect included a known datum and an initial baseline measurement was taken before the current was initiated. After each experiment a detailed scan of the whole substrate surface was made over a 530 x 280 $\mathrm{mm}$ area (10 x $10 \mathrm{~mm}$ grid).

\section{RESULTS}

\subsection{Final 3D Morphology}

Figure 2 shows contour plots of the final sediment surface. The Sand run exhibits the greatest degree of scour around the monopile in terms of its depth and lateral extent. The scour zone is conical in shape with smooth sides. Scour is also evident at the downstream lip of the sediment tray, indicating that the lee-wake vortices are capable of erosion well beyond the downstream extent of the substrate. This resulted in local erosion not directly associated with the monopile and 'clear water' conditions were maintained throughout. Scour depth and gradient are greatest on the stoss side, but the lee side scour zone extends further with a shallower but constant gradient, typical of scour around monopiles (e.g. Sumer \& Fredsøe 2012).

Clay contents of $2.5 \%$ and $5 \%$ yield a progressive reduction in scour extent in all directions. However, final morphologies remain similar in form, if not scale, to the Sand run, i.e. smooth sides, similar asymmetrical distribution and deposits along the centreline in the lee. Notably, secondary scour is limited to the lip of the sediment tray and does not influence the centreline transect. The relative size of the scour hole continues to diminish as clay content exceeds $10 \%$. The scour morphology becomes increasingly irregular (see Debnath \& Chaudhuri 2010; Ting et al. 2001), with different 'lobes' of erosion exhibiting multiple slope angles becoming more prominent at higher clay contents. The sides of the slope become significantly steeper, an observation made elsewhere in mixed cohesive substrata (Molinas \& Hosny 1999). 


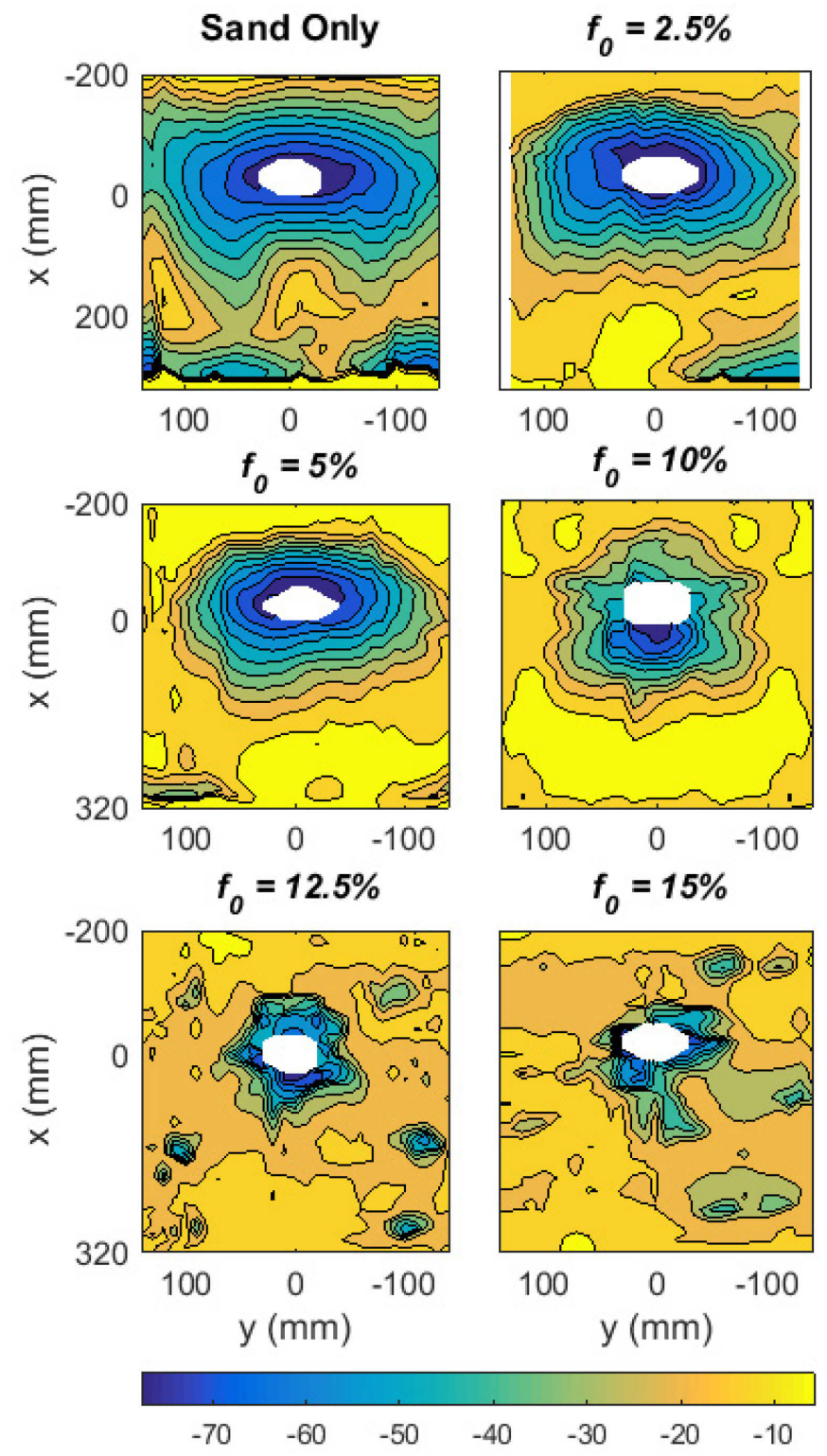

Figure 2. Contour plots of surface morphology after each experiment. Depth values in $\mathrm{mm}$. Percent values are clay content by percent mass, $f_{0}$.

\subsection{Scour Depth}

Maximum scour depth, $S_{\max }$, along each transect was determined for each point in time, $t$. In each case this was located at the monopile, typically on the stoss side. Time development curves of maximum scour depth normalised by monopile diameter, $S_{\max } / D$, are shown in Fig. 3(a). Note the variation in experi- mental duration (Sand, $f_{0}=12.5 \%, 15 \%=5 \mathrm{~h}$; $2.5<f_{0}<10=3 \mathrm{~h}$ ). The time development of the depth of scour occurs rapidly initially due to the strong feedback effect of flow turbulence (Debnath \& Chaudhuri 2010), tending asymptotically with time to its ultimate value through an exponential decaying time dependence (e.g. Soulsby 1997). However, we need to determine whether cohesion merely limits the rate of scour, ultimately yielding the same equilibrium form (see Briaud et al. 1999) or whether cohesion modifies the physical processes causing erosion to limit final scour depth compared to cohesionless materials, an effect seen elsewhere in bedform development in mixed-cohesive sediments (Schindler et al. 2015). In order to assess whether scour depth has reached equilibrium values, and ultimately derive equilibrium values for each experiment, a curve of the following form

$S_{\max } / D(t)=S_{\text {eqm }} / D\left(1-e^{-t / T s}\right)$

was applied to the time-development curves of $S_{\max } / D$ to yield equilibrium normalised scour depth, $S_{\text {eqm }} / D$, and timescale of scour, $T_{s}$ (after Whitehouse et al. 2006). The fits minimise mean absolute difference between measurements. To provide comparison between experiments of different durations experiments lasting $5 \mathrm{~h}$ were also subject to analyses of the data collected during the initial $3 \mathrm{~h}$. Resulting curves are superimposed on the data in Figure 3(a). Table 1 shows $S_{\text {eqm }} / D, T_{s}$ and associated $\mathrm{R}^{2}$ values, where values in parentheses are from $3 \mathrm{~h}$ data sets where relevant.

Broadly, equilibrium scour depths are inversely related to $f_{0}$. Comparison of curves for Sand, $f_{0}=$ $12.5 \%$ and $15 \%$ shows little difference in fits for $3 \mathrm{~h}$ and $5 \mathrm{~h}$ data with comparable $\mathrm{R}^{2}$ values, confirming that $3 \mathrm{~h}$ was sufficient duration to reach equilibrium scour depth across all experiments at this current speed. The poorest fits occur for the Sand and $f_{0}=$ $2.5 \%$ cases (both $R^{2}<0.67$ ). This is surprising given that Equation 1a is derived for effectively cohesionless material. The main cause of the poor fit is in the period 20 mins $<t<80$ mins where $S_{\max } / D$ is constantly below predicted values. Excellent fits are seen for $5 \%<f_{0}<12.5 \%\left(R^{2}>0.85\right)$. For $f_{0}=15 \%$ $R^{2}=0.73(0.82$ over $3 \mathrm{~h})$ with the main deviation relating to the period $20 \mathrm{~min}<t<80 \mathrm{~min}$ noted above.

Table 1. Equilibrium scour variables derived from best-fit relationship of $S_{\max } / D$ and $E / \mathrm{D}$ over time, $t$. Experiments $1,5 \& 6$ lasted $5 \mathrm{~h}$. Values in parentheses are based on initial $3 \mathrm{~h}$ data for comparison to Experiments $2-4$. Bold = values used in Figures 4 \& 5.

\begin{tabular}{|c|c|c|c|c|c|c|c|c|c|}
\hline Exp. & $\begin{array}{c}\text { Duration } \\
\mathrm{h}\end{array}$ & ${ }_{\%} f_{0}$ & ${ }^{\tau}$ & $S_{\text {eqm }} / D$ & $T_{s}$ & $\mathrm{R}^{2}$ & $E_{\mathrm{m}} E_{\text {eqm }} / D$ & $\min ^{T e}$ & $\mathrm{R}^{2}$ \\
\hline 1 & 5 & 0 & 1.04 & 1.61(1.56) & $5.2(4.3)$ & $\mathbf{0 . 5 5}(0.48)$ & $241.9(\mathbf{2 3 0 . 5})$ & $34.9(\mathbf{1 4 . 1})$ & $0.93(\mathbf{0 . 7 0})$ \\
\hline 2 & 3 & 2.5 & 5.06 & 1.39 & 5.7 & 0.67 & 168.3 & 35.7 & 0.96 \\
\hline 3 & 3 & 5.0 & 5.29 & 1.33 & 6.7 & 0.93 & 123.1 & 45.6 & 0.93 \\
\hline 4 & 3 & 10.0 & 8.40 & 0.84 & 11.8 & 0.95 & 90.0 & 24.3 & 0.91 \\
\hline 5 & 5 & 12.5 & 8.21 & $\mathbf{0 . 3 5}(0.36)$ & $19.1(34.5)$ & $\mathbf{0 . 8 5}(0.95)$ & $68.9(68.0)$ & $\mathbf{4 0 . 3}(37.83)$ & $\mathbf{0 . 9 9}(0.98)$ \\
\hline 6 & 5 & 15.0 & 8.44 & $0.26(0.25)$ & $15.1(10.8)$ & $\mathbf{0 . 7 3}(0.82)$ & $54.8(51.69)$ & $148.2(96.16)$ & $0.95(0.86)$ \\
\hline
\end{tabular}




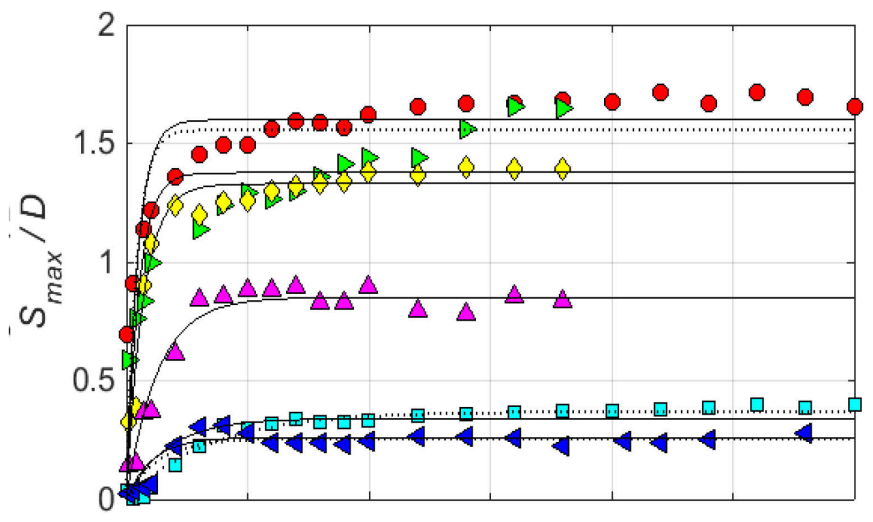

- Sand $\triangleright 2.5 \% \diamond 5 \% \Delta 10 \% \quad \square \quad 12.5 \% \quad 15 \%$ -

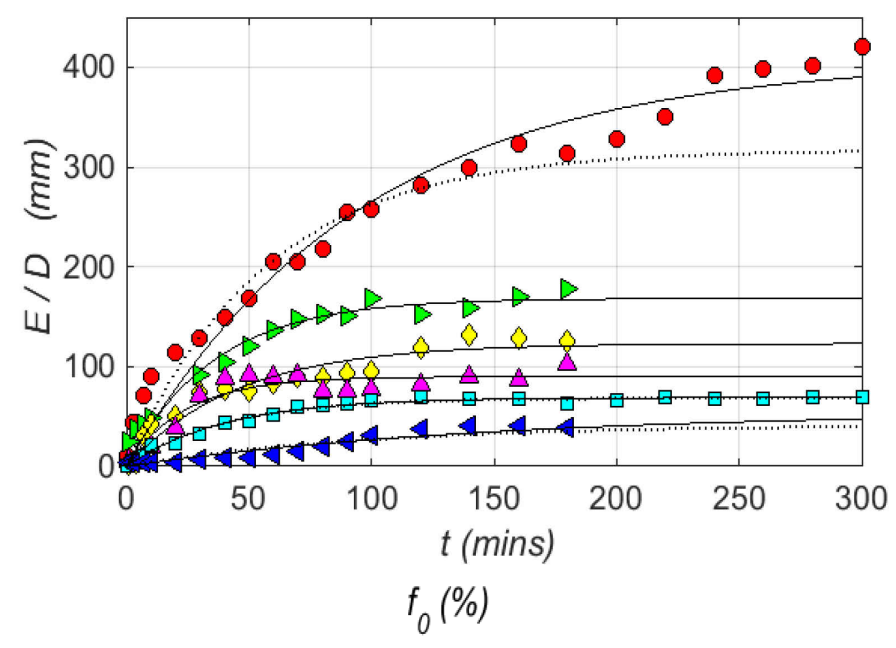

Figure 3. Change in (a) normalized maximum scour depth, $S_{\max } /$ $D$, and (b) normalized excavation area, $E / D$ including best-fit curves. The dashed lines indicate best-fit curve based on $3 \mathrm{~h}$ data for experiments lasting $5 \mathrm{~h}$.

\subsection{Excavation Area}

While $S_{\max }$ is a key parameter in any scour evaluation it is important to recognise that it is a single value representative of one point in space and its use is dependent on the consistency of form, i.e. conical scour pit, seen in previous experiments in cohesionless substrates. Given that qualitative evaluations shows the increasingly irregular and 'blocky' appearance of the final form it is also informative to consider the amount of material excavated during scour development.

The excavation area, $E$ (defined as the area of material lost below the baseline along the centreline transect), was determined for each point in time for each run. The same form of curve was used to establish normalised equilibrium excavation area, $E_{\text {eqm }}$, and timescale of excavation, $T_{e}$, modified as:

$E / D(t)=E_{\text {eqm }} / D\left(1-e^{-t / T e}\right)$

The observations and fitted curves are shown in Figure 3(b) and Table 1. The strength of the relationships confirms the suitability of the modified equation. In fact, $\mathrm{R}^{2}>0.90$ in all experiments, suggesting that the curve better fits $E / D$ than $S_{\max } / D$ data. In Figure 3(a) we saw that $S_{\max } / D$ curves for the Sand case over $3 \mathrm{~h}$ and $5 \mathrm{~h}$ were very similar. Here we see that they deviate significantly at $t>100 \mathrm{~min}$. The difference is the result of secondary scour that occurred at the lip of the sediment tray in the later stages of the experiment. Because the calculation of $E$ considers all sediment loss along the centreline the notable, stepped increase in values after $t=220 \mathrm{~min}$ reflects secondary scour excavation at the lip. Consequently, the $3 \mathrm{~h}$ curve better reflects the loss of material due to primary scour around the monopile and from this point $3 \mathrm{~h}$ values of $E_{\text {eqm }} / D$ and $T_{e}$ are used to describe equilibrium excavation values in the Sand experiment.

Notably, $3 \mathrm{~h}$ and $5 \mathrm{~h}$ curves from $f_{0}=12.5 \%$ and $15 \%$ are almost identical, again confirming that $3 \mathrm{~h}$ was sufficient to capture equilibrium morphologies across all experiments. Comparison of values in Table 1 confirms the similarity in $E_{\text {eqm }} / D$ values for different durations. The $E_{\text {eqm }} / D$ curves show a similar developmental form to $S_{\text {eqm }} / D$ curves but it is notable that it takes longer in each experiment for the values to asymptote. This is reflected in $T_{e}$ values which are an order of magnitude larger than $T_{s}$ values. However, values for the timescale of excavation, $T_{e}$, vary significantly suggesting Eqt. $1 \mathrm{~b}$ may be unsuitable for determining excavation timescales.

\subsection{Relationship to Clay Content \& Shear Strength}

The relationships between $f_{0}$ and equilibrium scour values are shown in Figure 4. In Figure 4(a) $f_{0}$ is strongly and inversely linearly related to $S_{\text {eqm }} / D$ and $E_{\text {eqm }} / D$. In Figure 4 (b) $T_{s}$ also exhibits a strong, linear relationship with $f_{0}$ despite an outlying value for $f_{0}$ $=12.5 \%$. Conversely, $24.3 \mathrm{~min}<T_{e}<45.6 \mathrm{~min}$ where $f_{0}<15 \%$ and changes in $T_{e}$ do not correspond to increases in $f_{0}$. Furthermore, for $f_{0}=15 \%, T_{e}$ increases substantially to $148.2 \mathrm{~min}$. This suggests that the application of Equation $1 \mathrm{~b}$ may be unsuitable for higher clay contents, regardless of the very good fit shown in the curve fitting procedure. Linear regression relationships between mean surface shear strength, $\tau$, and equilibrium scour values are shown in Figure 5. With the exception of $E_{\text {eqm }} / D$, each variable shows a weaker relationship to $\tau$ than $f_{0}$.

Comparison of values in Table 1 reveals that $\tau$ is positively related to $f_{0}$ although the distribution of values is three-tiered. The Sand run has the lowest strength measured with the shear vane of $1.04 \mathrm{kPa}$. The addition of clay at $f_{0}=2.5 \%$ yields a five-fold increase, to $5.06 \mathrm{KPa}$. In comparison, doubling the clay content to $f_{0}=5 \%$ yields a small increase in $\tau$, to 5.29 $\mathrm{KPa}$. A similar, non-proportional change is seen in $\tau$ where $10 \%<f_{0}<15 \%$, underlining the complex nature of mixed sand-clay bonding kinetics. Values are around $8.5 \mathrm{KPa}$, with the highest shear strength exhibited by $f_{0}=15 \%$. A curve fitting exercise (not shown) revealed that the relationship was better described by a $2^{\text {nd }}$ order power-law $\left(\mathrm{R}^{2}=0.97\right)$ than a linear fit $\left(\mathrm{R}^{2}=0.81\right)$. 

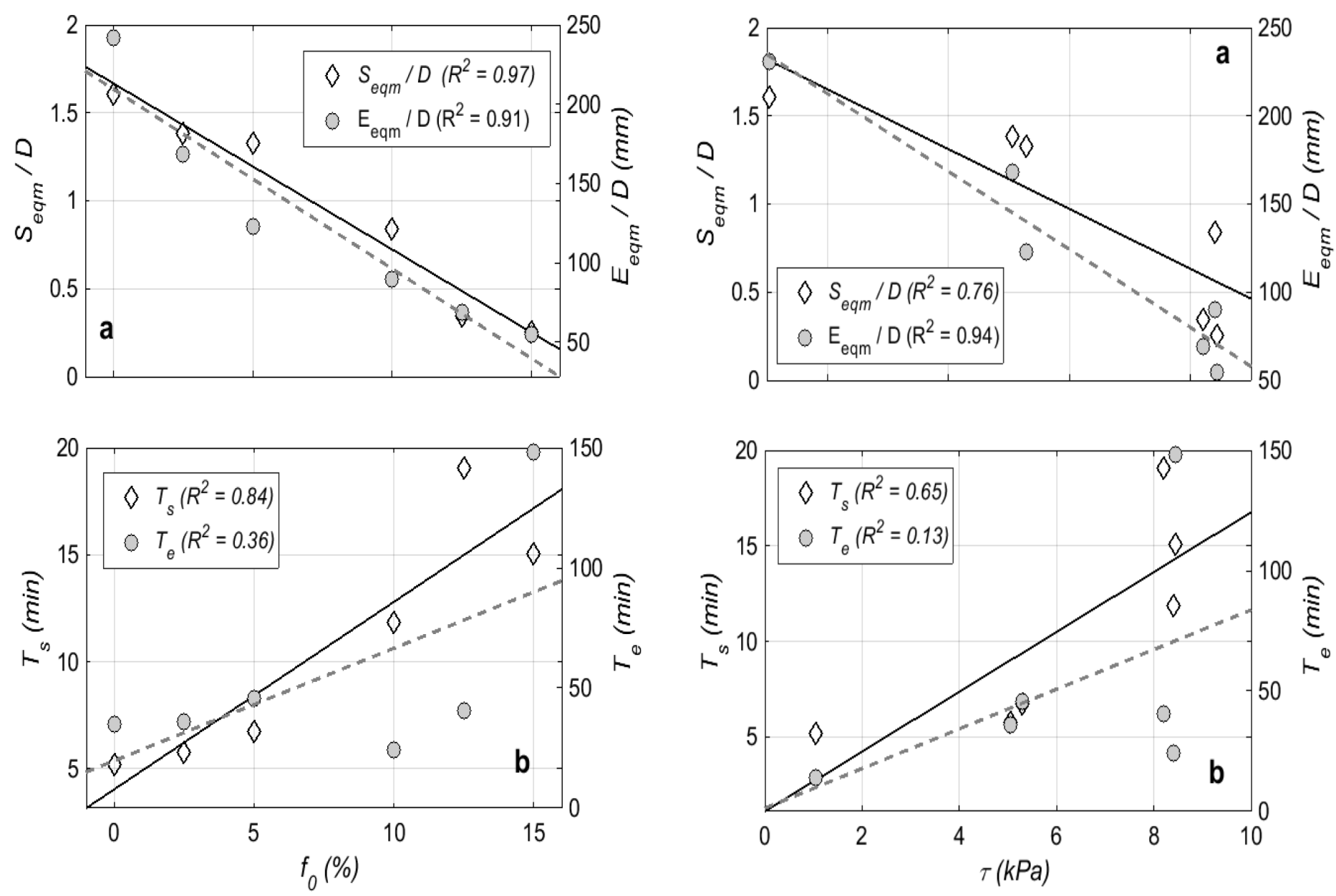

Figure 4. Relationship between initial clay content, $f_{0}$, and (a) normalized equilibrium scour depth, $S_{\text {eqm }} / D$, and normalized equilibrium excavation area, $E_{\text {eqm }} / D$; (b) timescale of scour, $T_{s}$, and timescale of excavation, $T_{e}$.

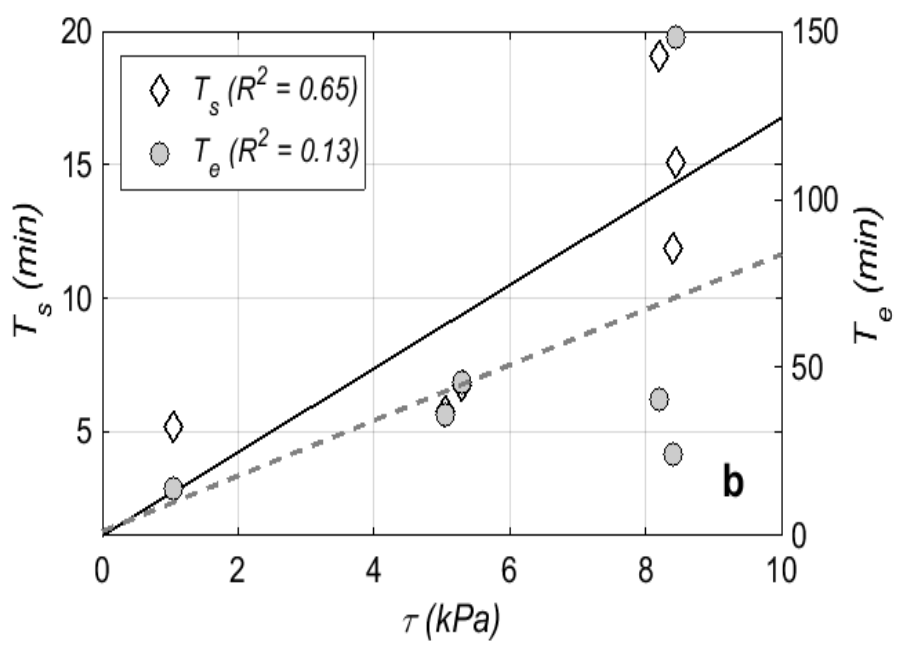

Figure 5. Relationship between surface shear stress, $\tau$, and (a) normalized equilibrium scour depth, $S_{\text {eqm }} / D$, and normalized equilibrium excavation area, $E_{\text {eqm }} / D$; (b) timescale of scour, $T_{s}$, and timescale of excavation, $T_{e}$.

\section{DISCUSSION}

\subsection{Importance of Clay Content}

The experiments conclusively prove that physical cohesion imparted by clay modifies scour dynamics in an otherwise cohesionless sediment matrix. Increasing clay content causes a clear, progressive reduction in scour depth, the area subject to scour and hence volume of excavated material. Equilibrium scour depth is reached before the excavated area has reached equilibrium and timescales of excavation are one order of magnitude greater than for scour depth.

The findings directly contradict the notion that the equilibrium scour depth may be the same for clay and for sand, only the scour rate differs (e.g. Briaud et al. 1999) and broadly concur with results presented by Molinas \& Hosny (1999), Ansari et al. (2002) and Rambabu et al. (2003). The disparity in equilibrium scour morphology between clay contents is because the strength of the network structure for sand-clay matrices depends on the relative proportions of each component (Mitchener et al. 1996).

Equilibrium scour characteristics are linearly related to both clay content and shear strength. However, the relationships are stronger for clay content. Schindler et al. (2015) revealed similar, strong linear relationships between clay content and the equilibrium height, length and steepness of subaqueous dunes across the same range of clay content.

Similarly, Baas et al's. (2013) examination of ripple development over beds of fine sand and (kaolin) clay determined that ripple height decreases as bed clay fraction is increased. Thus, the use of clay content by percent mass may offer a simple index where geotechnical parameters are not required - on which to model scour in unconsolidated mixedcohesive sands, at least until $f_{0} \sim 15 \%$.

Relationships based on the well-known scaling between equilibrium scour depth and monopile diameter should be modified to include a factor that accounts for cohesive effects based on clay content. 


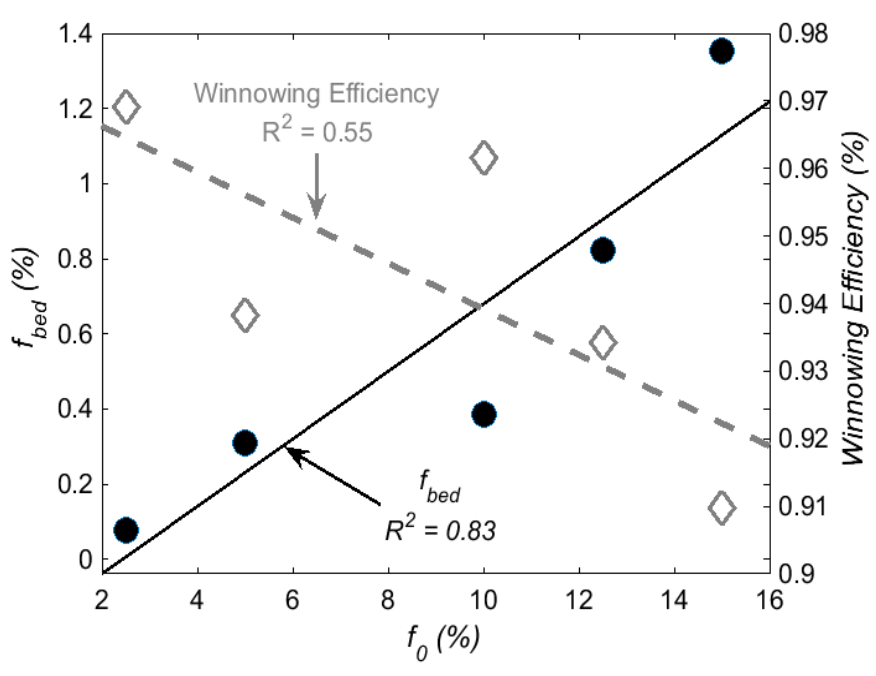

Figure 6. Comparison of bedload clay content, $f_{\text {bed }}$, (circles, solid line) and Winnowing Efficiency (diamonds, dashed line) across different clay contents. Not applicable to Sand Only run.

\subsection{Clay Content \& Shear Strength}

The relative weakness of the relationship between scour characteristics and shear strength lies primarily in the similarity of shear strength across $10 \%<f_{0}<$ $15 \%$. We may speculate that this range includes the boundary between grain and matrix supported substrata. For a grain supported matrix an increased resistance to erodibility may be attributed to the filling of void space by weakly bonded clay particle stacks (Tolhurst et al. 2002). In matrix supported cases the sand particles are not in contact with each other and the clay component controls the erodibility of the sediment mixture.

Baas et al. (2013) also identify a similar boundary in the formation of current ripples. Equilibrium heights are linearly related to clay content until $f_{0}>$ $13 \%$ whereupon they become significantly smaller, a facet they attribute to a shift from a grain to matrix a supported sediment where erosion is beyond the direct control of clay content.

It is also notable that the equilibrium morphologies of each experiment shift from a conical shape with smooth sides to an irregular, lobed form with near-vertical slopes where $f_{0} \geq 10 \%$ (Fig. 2). The increase in slope steepness can be related to an increase in the angle of internal friction as clay is added to the matrix (Panagiotopoulos et al. 1997). We must also consider that irregularity may result from a shift in erosion mode from winnowing (selective removal) of clay from the sand which causes excavation of individual sand and clay particles to a model where sandclay aggregate removal dominates.

\subsection{Winnowing \& Scour Limitation}

At present a clear understanding of the erosion of sand-clay mixtures remains elusive. Two broad mechanisms have been postulated: (1) the particles move individually (e.g. Jacobs et al. 2011) or (2) chunks of sand-clay aggregates are removed incrementally (e.g. Debnath et al. 2007).

Figure 6 shows the results of the grain size analyses undertaken on final bedload deposits for all clay runs. The regression relationship between initial clay content, $f_{0}$, and bedload clay content, $f_{\text {bed }}$ reveals that all bedloads exhibit a marked reduction in clay content compared with initial concentrations and that $f_{\text {bed }}$ is strongly positively related to $f_{0}\left(R^{2}=0.83\right)$. Winnowing efficiency (Fig. 6(b), where $0 \%$ is no clay removed and $100 \%$ is all clay removed) is above $90 \%$ in all cases and there is moderate, negative relationship $\left(R^{2}=0.55\right)$ between winnowing efficiency and $f_{0}$.

The absence of clay within the bedload suggests that aggregation is limited. However, individual grain movement is selective. Instead, winnowing of clay occurs during scour development and we can infer that winnowing is required before sand entrainment i.e. scour erosion can occur. This indirectly contradicts the theory that surface erosion is time independent, where individual sand and mud particles are simultaneously and uniformly eroded (e.g. Jacobs et al. 2011). Further, it shows winnowing of the clay from the matrix dominates over sand-clay aggregate removal seen elsewhere at higher clay concentrations (e.g. Debnath \& Chaudhuri 2010). It is reasonable to assume that winnowing therefore causes the temporal increase in scour depth and extent in a manner analogous to the temporal increase in height and wavelength of ripples seen by Baas et al. (2013) where winnowing efficiency was $82-100 \%$ across similar clay contents.

Initially the uppermost layer of sediment is exposed directly to the flow. Winnowing is triggered when the flow is sufficiently strong to entrain clay particles. Liberated sand grains are no longer restricted by clay particles filling voids and become mobile, exposing the next layer of sediment for winnowing. Turbulence structure around a monopile in a current causes a large spatial gradient in mean and instantaneous stresses acting on the sediment surface (Sumer $\&$ Fredsøe 2012). The winnowing rate, likely proportional to these stresses, is therefore maximized at the monopile where the horseshoe vortex system is focussed. With distance from the monopile the stresses decline until, ultimately, they are not sufficient to cause winnowing.

The self-limiting nature of scour around a monopile is well known (e.g. Sumer \& Fredsøe 2012). The timescale of scour increases with clay content because there are fewer voids, a greater number of clay bonds to break and more clay particles to remove. The spatial extent of the scoured area is also controlled in this manner. Because the current, depth and slope are the same between experiments the distribution of stresses remains constant (albeit with the 
evolving scour morphologies modifying the local flow domain). Therefore the distance from the monopile at which the flow is capable of initiating erosion through winnowing diminishes as clay content increases.

Differential local winnowing rates across the sediment surface may also explain the different timescales of scour and excavation. The capacity to winnow clay and entrain sand particles is maximized at the monopile primarily due to the intensity of the horseshoe vortex system and secondary turbulent structures. Thus, while the maximum scour depth is realised at the monopile rapidly, winnowing rates will diminish with distance from the monopile. Consequently, under clear water conditions, the liberation of sand particles available for entrainment will diminish in rate until a distance where the pressure gradient is no longer sufficient to generate stresses that cause winnowing, and hence erosion.

\subsection{Industrial Use}

An improved understanding of scour in mixedcohesive sediments is highly informative given the potential reduction in both CAPEX and long-term operational (OPEX) costs. The results presented herein indicate that use of predictors for maximum scour depth and area based on clay-influenced soils may lead to foundation designs and scour protection measures for waterway, coastal and offshore structures that are unnecessarily conservative. A consideration of physical cohesion needs to be incorporated into scour predictions as, at present, these effects are poorly considered and not widely realised. The use of clay content by percent mass offers a simple index on which to modify existing predictive models designed for cohesionless materials for unconsolidated mixedcohesive sands.

Improved predictions of scour development can reduce manufacturing costs and related logistical expenses such as ship and jack-up barge costs. If scour is limited in depth and extent by the influence of clay shallower embedment foundations may be possible subject to the usual geotechnical and structural analyses. More accurate predictions of scour development could reduce OPEX costs by reducing the frequency and extent of scour surveys.

\subsection{Future Work}

The subject requires further examination so that a clearer understanding of scour for multi-modal sediment distributions (e.g. Briaud et al. 2003), layered sediments (e.g. Harris et al. 2010) and different degrees of compaction (e.g. Molinas \& Hosny 1999), water content (e.g. Debnath \& Chaudhuri 2010) and shear strength (Harris and Whitehouse 2014) influence scour dynamics. Furthermore, we must also examine scour in a range of flow environments that in- clude unsteady currents, wave-driven oscillatory flow and different boundary layer depths.

Kaolin clay offers very weak bonding kinetics compared with other clays and the results presented herein may actually represent the lower threshold in how physical cohesion influences scour dynamics (e.g. Alizadeh 1974). In addition, electrostatic bonding would increase with salinity, in turn increasing the zeta potential (a measure of the net electrical charge around particles) of clay particles and further accentuating resistance to erosion (Mietta et al. 2009). Finally, the precise mechanisms of erosion require further elucidation, specifically the relative importance of winnowing and aggregate/floc erosion as clay content changes (e.g. Van Ledden et al. 2004).

\section{CONCLUSION}

We present experiments that examine the effects of physical cohesion from clays on scour dynamics around a monopile. The results show that physical cohesion reduces the overall rate, extent and maximum depth of scour around monopiles in unconsolidated sands when subject to a steady current. Furthermore, equilibrium scour morphology becomes increasingly irregular with steeper slopes. Ultimately, in our tests, a clay content of $10 \%$, which is not atypical of UK coastal waters (Healey et al. 2001), is sufficient to halve the equilibrium scour depth and reduce the excavated area along a centreline orientated to the current by $\sim 75 \%$.

While physical cohesion is positively related to shear strength, it is clay content rather than that increase in shear strength which is better related to key parameters describing scour evolution. This is principally because shear strength is similar for clay contents between $10 \%-15 \%$, suggesting that the sediment switches from a grain to a matrix supported structure.

Winnowing of clay from the sand matrix is required in order to liberate sand grains which are then entrained and transported, resulting in scour. Differences in equilibrium scour depth, timescales of scour and the area of scour between substrata result from the increased critical stress of sediment as clay is added.

The effects of physical cohesion imparted by clays and silt within an otherwise cohesionless sediment matrix are rarely included in current predictions of scour morphology despite the clear design and construction implications for coastal and offshore structures. The strong, linear relationships between clay content and equilibrium scour depth, timescale of scour and excavation area offer a simple means in which physical cohesion could be incorporated into existing predictive methods for final scour morphologies to supplement detailed geotechnical information, offering a method of optimizing the future 
design and construction of structures in fluvial, coastal and offshore environments.

\section{ACKNOWLEDGEMENTS}

This study was made possible by the Marine Institute, Plymouth University through Round V of the Higher Education Innovation Fund (HEIF V). The authors are indebted to the COAST laboratory technical staff, especially Alastair Reynolds and Peter Arber. RJSW and JMH acknowledge funding from the HR Wallingford strategic research programme.

\section{REFERENCES}

Annandale, G.W. 1995. Erodibility, Journal of Hydraulic Research 33: 471-494.

Ansari, S.A., Kothayri, U.C. \& Ranga Raju, K.G. 2002. Influence of cohesion on scour around bridge piers. Journal of Hydraulic Research 40: 717-729.

Ariathurai, R. \& Arulanandan, K. 1974. Erosion Rates of Cohesive Soils. Journal of the Hydraulics Division, ASCE 104: 279-283.

Baas, J. H. Davies, A. G. \& Malarkey, J. 2013. Bedform development in mixed sandmud: the contrasting role of cohesive forces in flow and bed. Geomorphology 182: 19-32.

den Boon, J.H. Sutherland, J. Whitehouse, R. Soulsby, R. Stam. C.J.M. Verhoeven. K. Hogedal. M. \& Hald, T. 2004. Scour behaviour and scour protection for monopile foundations of offshore wind turbines. Proc. 2004 Wind Energy Conference. London: Curran.

Briaud, J.L., Ting, C.K. Chen, C. Gudavalli, Suresh, P. Wei, G. 1999. SRICOS: Prediction of scour rate in cohesive soils at bridge piers. Journal of Geotechnical and Environmental Engineering 125(4): 237-246.

The Carbon Trust 2014. Offshore Wind Accelerator: Driving down the cost of offshore wind. DECC.

Dade, W.B. Nowell, A.R.M. Jumars, P.A. 1992. Predicting erosion resistance of muds. Marine Geology 105: 285- 297.

Debnath, K., Aberle, J., Nikora, V.,Westrich, B. \& Muste, M. 2007. Erosion of cohesive sediments: Re-suspension, bed load, and erosion patterns from field experiments. Journal of Hydraulic Engineering 133: 508-520.

DNV 2010. Design of offshore wind turbine structures. DNVOS-J101. Det Nordske Veritas, Det Norske Veritas Classification $\mathrm{A} / \mathrm{S}$.

Dunn, I. S. 1959. Tractive resistance to cohesive channels. J. Soil Mech. and Found. Div. ASCE 853: 1-24.

Harris, J.M. Whitehouse, R.J.S. \& Sutherland, J. 2010. Scour assessment in complex marine soils - an evaluation through case examples. Proc. $5^{\text {th }}$ In. Conf. Scour \& Erosion, ASCE Geotechnical Special Publication 210: 450 - 459.

Harris, J.M. \& Whitehouse, R.J.S. 2014. Marine scour: Lessons from nature's laboratory. In Liang Cheng, Scott Draper, Hongwei An (eds.), Proceedings of the Seventh International Conference on Scour and Erosion, Perth, Western Australia, 2 - 4 December 2014. London: Taylor \& Francis.

Healy, T. Wang, Y. \& Healy, J.A. 2002. Muddy Coasts of the World: Processes, Deposits and Function. Amsterdam: Elsevier.
Jacobs, W. Le Hir, P. Van Kesteren, W. \& Cann, P. 2011. Erosion threshold of sand-mud mixtures. Cont. Shelf Res. 31: S14-S25.

Kothyari, U,C. 2008. Bridge scour: status and research challenges. ISH Journal of Hydraulic Engineering 14: 1-27.

van Ledden, van Kesteren. W.G.M. \& Winterwerp, J.C. 2004. A conceptual framework for erosion behaviour in sand-mud mixtures. Cont. Shelf. Res. 24: 1-11.

Lyle, W. M. \& Smerdon, E. T. 1965. Relation of compaction and other soil properties to erosion and resistance of soils. Trans. American Society of Agricultural Engineers, 8(3).

Mehta, A.J. 1993. Nearshore and Estuarine Cohesive Sediment Transport. AGU, Washington, DC.

Melville, B.W. 1997. Pier and abutment scour: integrated approach. Journal of Hydraulic Engineering 123, 125-136.

Mitchener, H.J., Torfs, H. and Whitehouse, R.J.S. 1996. Erosion of mud/sand mixtures. Coastal Engineering 29, 1-25. [Erratum, Vol.30, (1997), 319].

Molinas, A. \& Hosny, M.M. 1999. Experimental study on scour around circular piers in cohesive soil. FHWA-RD-99-186, Federal Highway Administration, US Department of Transport, McLean, VA.

Panagiotopoulos, I. G. Voulgaris, \& M. B. Collins. 1997. The influence of clay on the threshold of movement of fine sandy beds. Coastal Engineering 32: 19-43.

Parsons, D.R. Schindler, R.J. Hope, J.A. Malarkey, J. Baas, J.H. Peakall;, J, Manning, A.J. Ye, L, Simmons, S. Paterson, D.M. Aspden, R. Bass, S.J. Davies, A.G. Lichtman, I.D. \& Thorne, P.D. 2016. The unrecognized role of bio-physical cohesion on subaqueous bedform size. Geophysical Res. Letters 43: doi:10.1002/2016GL067667.

Partheniades, E. 1965. Erosion and Deposition of Cohesive Soils. Journal of the Hydraulics Division, ASCE 4204: 105138.

Renewables Advisory Board 2010. Value-breakdown-offshorewind-sector.

Rambabu, M. Narasimha Rao, S \& Sundar, V. 2003. Currentinduced scour around a vertical pile in cohesive soil. Ocean Engineering 30: 893-920.

Richardson, E. V. \& Davis.S. R. 1995. Evaluating scour at bridges. Rep. No. FHWAIP_-90-017 (HEC 18). Washington: Federal Highway Administration.

Schindler, R. J. D. R. Parsons, L. Ye, J. A. Hope, J. H. Baas, J. Peakall, A. J. Manning, R. J. Aspden, J. Malarkey, S. Simmons, D. M. Patterson, I. D. Lichtman, A. G. Davies, P. D. Thorne, \& S. J. Bass 2015, Sticky stuff: Redefining bedform prediction in modern and ancient environments. Geology 43: 399-402, doi:10.1130/G36262.1.

Sheppard, D.M., Odeh, M. \& Glasser, T. 2004. Large scale clear water local pier scour experiments. Journal of Hydraulic Engineering 130: 957-963.

Smerdon, E. T. \& Beasley, R. P. 1959. Tractive force theory applied to stability of open channels in cohesive soils. University of Missouri Agricultural Experiment Station, Res. Bull. 715.

Soulsby, R.L. 1997. Dynamics of Marine Sands. London: Thomas Telford.

Sumer, B.M. \& Fredsøe, J. 2012. The mechanics of scour in the marine environment, Singapore: World Scientific.

Ting, F.C.K., Briaud, J.L., Chen, H.C., Gudavalli, R., Perugu, S. $\&$ Wei, G. 2001. Flume tests for scour in clay at circular piers. Journal of Hydraulic Engineering 127: 969-978.

Tolhurst, T. J. Gust, G. \& Paterson, D. M. 2002. The influence of an extracellular polymeric substance (EPS) on cohesive 
sediment stability. Proceedings in Marine Science 5: 409425.

Van den Eynde, D. Brabant, R. Fettweis, M. Francken, F. Melotte, J. Sas, M. \& Van Lancker, V. 2010. Monitoring of hydrodynamic and morphological changes at the C-Power and Belwind offshore wind farm sites: A synthesis. In S. Degraer et al. (eds.), Offshore wind farms in the Belgian part of the North Sea: Early environmental impact assessment and spatio-temporal variability: 19-36.

van Ledden, van Kesteren. W.G.M. \& Winterwerp, J.C. 2004. A conceptual framework for erosion behaviour in sand-mud mixtures. Cont. Shelf. Res. 24: 1-11.

Whitehouse R.J.S. Soulsby R.L. Roberts W. \& Mitchener H.J., 2000. Dynamics of Estuarine Muds. London: Thomas Telford.

Whitehouse, R.J.S. Sutherland, J. \& O’Brien, D. 2006. Seabed scour assessment for offshore windfarms. Proceedings of the $3^{\text {rd }}$ Int. Conference on Scour and Erosion. Amsterdam: Elsevier.

Whitehouse, R.J.S. Harris, J.M. Sutherland, J. \& Rees, J. 2011. The nature of scour development and scour protection at offshore windfarm foundations, Marine Pollution Bulletin 62: 73-88.

Yanmaz, A.M. Altinbilek, H.D. 1991. Study of Time-dependent Local Scour around Bridge Piers. Journal of Hydraulic Engineering 117(10): 1247-1268. 